\title{
Death of Paediatric Surgical Patients in NICU of CMH, Dhaka
}

Islam $\mathrm{ADMS}^{1}$, Khan $\mathrm{SE}^{2}$, Yasmeen $\mathrm{S}^{3}$, Nira JA ${ }^{4}$

DOI: https://doi.org/10.3329/jafmc.v16i1.53829

\begin{abstract}
Introduction: The purpose of this study was to explore clinical characteristics and primary surgical diagnosis associated with in-hospital death in pediatric surgical patients admitted to the neonatal intensive care unit (NICU) of Combined Military Hospital (CMH), Dhaka.
\end{abstract}

Aim: To explore the clinical factors associated with in-hospital death in paediatric surgical patients admitted to the NICU over a period of 4 years in $\mathrm{CMH}$ Dhaka.

Methods: This retrospective study includes all patients admitted to NICU of CMH Dhaka for paediatric surgical diseases between July 2013 and December 2017. Data analyzed to asses factors associated with in-hospital death.

Results: A total of 72 cases were included and 61(84.7\%) underwent surgery. Fifteen patients (20.8\%) died while hospitalized in the NICU. The 5 most common surgical diagnoses were Anorectal Malformation, Intestinal Atresial Stenosis, Hirschsprungs disease, Intestinal perforation and meconium related obstruction. Esophageal atresia, necrotizing entero-colitis cases had the highest mortality rate.

Conclusion: This study describes EA, NEC, Low birth weight (LBW), prematurity and caesarean delivery associated with significant number of deaths of surgical patients in NICU. Novel approaches for these conditions are required to improve the survival.

Key-words: Death, Paediatric Surgical patients, Neonatal intensive care unit (NICU).

\section{Introduction}

Of the estimated 130 million infants born each year worldwide ${ }^{1,4}$ million die in the first 28 days of life. Three quarters of neonatal deaths occur in the first week and more than one quarter in the first 24 hours $^{1,2}$. Neonatal death, account for $40 \%$ of the total death under the age of 5 years, worldwide. In Bangladesh, infant mortality rate ${ }^{3}$ is 39.55 per 1000 live births in 2018. In 1949, the overall mortality of neonatal surgery was $72 \%$ leading Peter Rickaw $^{4}$ to state that "Except in the hands of a very few, very expert surgeons, operating on a small number of highly selected cases, the mortality for major operative procedures was forbiddingly high". Over the last 6 decades there has been a striking reduction of mortality. Eight medical and industrial developments appear to be primarily responsible are: growth of pediatric surgery, growth of paediatric anesthesia, advances in neonatal physiology, establishment of the Neonatal Intensive Care Unit (NICU), invention of the transistor, advances in airway management and mechanical ventilation, introduction of total parenteral nutrition and discovery of antibiotics ${ }^{5}$. Further risk identifications and improvements are necessary to further reduce the mortality rate.

Previous reports show that preterm birth, out born status, congenital anomalies and surgery are associated with mortality in NICUS ${ }^{6-8}$. Attempts to stratify risk for individual congenital disorders such as Necrotizing Enterocolitis (NEC), Congenital Diaphragmatic Hernia (CDH), and Gastroschisis have been described $^{9-12}$ and efforts also have been made to identify perioperative risk factors for major complication or death after paediatric surgery ${ }^{13,14}$. The purpose of this study was to explore the clinical factors associated with in-hospital death in paediatric surgical patients admitted to the NICU over a period of 4 years in $\mathrm{CMH}$, Dhaka. Identifying clinical characteristics and primary surgical diagnoses might allow for more directed interventions in high risk patients and it might lead to reduce mortality in pediatric surgical patients admitted to the neonatal intensive care unit.

\section{Materials and Methods}

This was a retrospective study of all patients admitted to NICU CMH Dhaka for paediatric surgical diseases between July 2013 and December 2017. The study population included all infants hospitalized in the NICU with suspected surgical diseases. Patients were identified through NICU ledger of all surgical cases. Patients were followed until discharge or in-hospital death. The primary outcome was discharge or in-hospital death. Collected clinical characteristics included: gender, gestational age, birth weight, presence of prenatal diagnosis, location of delivery, mode of delivery, presence of congenital heart disease and whether the operation operation was emergent. The diagnoses were collected and categorized: Anorectal malformation (ARM), Intestinal atresia/stenosis, Hirschsprungs disease, CDH, EA, Intestinal perforation, Omphalocele, meconium related intestinal obstruction, Gastroschisis, NEC and Urinary system disorders. All statistical analyses were performed with SPSS version 19.0 and $p$ $<0.05$ was considered as statistically significant.

1. Col Abu Daud Md Shariful Islam, MBBS, FCPS, Classified Specialist in Surgery, Combined Military Hospital (CMH), Cumilla (E-mail: sharif936@yahoo.com) 2. Brig Gen Shams-ud-Din Elias Khan, MBBS, MS, Adviser Specialist in Surgery, CMH, Dhaka 3. Col Sabina Yasmeen, MBBS, DCH, FCPS, Classified Specialist in Paediatrics, CMH, Dhaka 4. Lt Col Julia Akhter Nira, MBBS, FCPS, Classifed Specialist in Gynaecology \& Obstetrics, CMH, Dhaka. 


\section{Results}

In total, 72 cases were included in this study. The clinical characteristics of the patients included in this study are summarized in Table-I. The male-to-female ratio was 1.48:1. Eleven (15.3\%) preterm (less than 32 weeks of gestation) infants and 12(16.7\%) extremely low birth weight (ELBW) (less than $1000 \mathrm{~g})$ infants were included. Twenty seven (37.5\%) patients were inborn (born in $\mathrm{CMH}$, Dhaka) and 45(62.5\%) were out-born (born outside $\mathrm{CMH}$, Dhaka). Emergency operation was performed in 37(51.4\%) patients. Fifteen (20.8\%) patients died in the NICU during the study period. Anorectal malformation and Intestinal atresia/stenosis ranked first and second in our study. All EA and NEC cases were surgical and had the highest mortality rate (75\%) and (67\%) respectively (Table-II). Preterm, ELBW, cesarean delivery, EA, CDH and NEC are significantly associated with in-hospital death in this study.

Table-I: Clinical characteristics of the patients $(n=72)$

\begin{tabular}{|c|c|c|c|}
\hline \multicolumn{2}{|c|}{ Characteristics } & Frequency & $\%$ \\
\hline \multirow{2}{*}{ Gender } & Male & 43 & 59.7 \\
\hline & Female & 29 & 403 \\
\hline \multicolumn{2}{|c|}{ Gestational age $<32$ weeks } & 11 & 15.3 \\
\hline \multicolumn{2}{|c|}{ Body weight $<1000 \mathrm{gm}$} & 12 & 16.7 \\
\hline \multicolumn{2}{|c|}{ Prenatal diagnosis } & 10 & 13.9 \\
\hline \multicolumn{2}{|c|}{ Out born } & 45 & 62.5 \\
\hline \multicolumn{2}{|c|}{ Caesarean delivery } & 30 & 41.7 \\
\hline \multicolumn{2}{|c|}{ Congenital Heart disease } & 9 & 12.5 \\
\hline \multicolumn{2}{|c|}{ Need for surgery } & 61 & 84.7 \\
\hline \multicolumn{2}{|c|}{ Emergent operation } & 37 & 51.4 \\
\hline \multicolumn{2}{|c|}{ In hospital death } & 15 & 20.8 \\
\hline
\end{tabular}

Table-II: Primary diagnosis of the patient $(n=72)$

\begin{tabular}{|l|c|c|}
\hline \multicolumn{1}{|c|}{ Characteristics } & Frequency & $\mathbf{~ \% ~}$ \\
\hline Anorectal malformation & 14 & 19.4 \\
\hline Intestinal atresia/ stenosis & 12 & 16.7 \\
\hline Hirschsprungs disease & 11 & 15.3 \\
\hline Intestinal perforation & 9 & 12.5 \\
\hline Meconium related obstruction & 6 & 8.3 \\
\hline Gastroscisis & 5 & 6.9 \\
\hline Esophageal atresia & 4 & 5.6 \\
\hline Congenital Diaphragmatic hernia & 3 & 4.2 \\
\hline Necrotising Enterocolitis & 3 & 4.2 \\
\hline Omphalocele & 3 & 4.2 \\
\hline Urinary system disorder & 2 & 2.8 \\
\hline
\end{tabular}

\section{Discussion}

In this study, we analyzed the data obtained from a 4-years single center experience beginning in July 2013 . The mortality rate while hospitalized in NICU in our study was $20.8 \%$. The male-to-female ratio was 1.48 . The total mortality rates in overall admission to $\mathrm{NICU}$ varied between countries. The overall in-hospital mortality rates $^{15}$ were reported to be from 3.1 to $29 \%$. Otake $\mathrm{K}$ et al reported $8.2 \%$ death rate among paediatric surgical patients admitted to the $\mathrm{NICU}^{16}$. One study in Bangladesh showed $10.61 \%$ mortality rate among paediatric surgery patients ${ }^{17}$. More males than females were admitted in our NICU for paediatric surgical diseases as other studies had reported ${ }^{6,7,15-17}$. Anorectal malformation, Intestinal Atresia/ stenosis and Hirschsprungs disease were the commonest diagnoses in this study. These are similar to other reported series ${ }^{7,16,17}$. Preterm birth, LBW, Cesarean delivery and diagnoses like CDH, NEC and EA are significantly associated with in-hospital death of pediatric surgical patients admitted to our NICU. The mortality rate of CDH has declined secondary to improvement in perinatal treatment and care including antihypertensive agents, gentle ventilation with high-frequency oscillatory ventilation, inhalation of nitric oxide and extracorporeal membrane oxygenation ${ }^{7,18}$. However, CDH continues to be a significant cause of neonatal morbidity and mortality due to pulmonary hypoplasia and pulmonary hypertension ${ }^{7,19}$. In some countries, "Clinical guidelines for Congenital Diaphragmatic Hernia of the newborn" was published in $2015^{20,21}$. The guidelines could provide adequate medical care for $\mathrm{CDH}$ patients by standardization of treatment and improve the survival rate of $\mathrm{CDH}^{21}$.

A previous large study ${ }^{9}$ reported that the mortality rate of NEC is high (13.1\%) especially in patients who underwent surgical treatment (30.8\%). Yamoto et al reported NEC and low gestational weight were associated with increased risk of death ${ }^{22}$. The main factors thought to be involved in the pathogenesis of NEC are intestinal immaturity, enteral feeds, the intestinal microbiome, inflammation and local ischemia and/or reperfusion injury ${ }^{23}$. Despite decades of research on NEC, its pathogenesis, efficient prevention or treatment are not fully understood. However, ongoing and planned clinical trials will allow us to routinely add targeted preventive measures, such as addition of prebiotics and probiotics, to the current management of high-risk infants, including human milk ${ }^{24}$. We had only 3 NEC patients in this study and this was a very number to make any generalized comment. LBW was a significant factor in this study. Recent progress in neonatal medical care, including minimally invasive surgery and body fluid management, has resulted in improvements in the survival of LBW infants ${ }^{7}$. However, LBW infants are fragile and tend to easily develop multi-organ failure due to shock ${ }^{7}$. Morriss et al reported major surgery is independently associated with death or neuro-development impairment in low birth weight infants ${ }^{25}$.

This study is subjected to the limitations inherent to all single institutional retrospective studies. Prospective data collection is required to overcome this limitation. This results may not be applicable to NICUs with patient populations that differ significantly from ours. Multicenter study is required to overcome this limitation.

\section{Conclusion}

This retrospective study showed CDH, NEC, EA and LBW are associated significant in-hospital death in surgical patients admitted to the NICU of a tertiary hospital. Novel approaches toward treatment are required to further decrease the mortality rates for those conditions. 


\section{References}

1. World Health Report 2005: Make every mother and child count. Geneva: WHO; 2005.

2. Lawn JE, Cousens S, Zupan J. 4 million neonatal deaths: when? Why? Lancet 2005; 365:891-900.

3. Geoba SE: Gazettere-Bangladesh-2018-statistics and ranking.

4. Rickshaw PP. Organization of a regional neonatal surgical service. In: Rickshaw PP, Johnston JH, eds. Neonatal Surgery, Newyork: AppeltonCentury-Crofts; 1969: 14-22.

5. Rowe MI, Rowe SA. The last fifty years of neonatal surgical management. Am J Surg 2000; 180:345-52.

6. Sankaran $\mathrm{K}$, Chien LY, Walker $\mathrm{R}$ et al. Variations in mortality rates among Canadian neonatal intensive care units. CMAJ 2002; 166:173-8.

7. Yagi $M, K o h n o M$, Asagiri $K$ et al. Twenty-year trends in neonatal surgery based on a nationwide Japanese surveillance program. Pediatr Surg Int 2015; 31:955-62.

8. Berry MA, Shah PS, Brouillette RT et al. Predictors of mortality and length of stay for neonates admitted to children's hospital neonatal intensive care units. J Perinatol 2008; 28:297-302.

9. Abdullah F, Zhang Y, Camp M et al. Necrotizing enterocolitis in 20,822 infants: Analysis of medical and surgical treatments. Clin Pediatr (Phila) 2010; 49:166-71.

10. Bucher BT, Guth RM, Saito JM et al. Impact of hospital volume on inhospital mortality of infants undergoing repair of congenital diaphragmatic hernia. Ann Surg 2010; 252:635-42.

11. Tsao K, Allison ND, Harting MT et al. Congenital diaphragmatic hernia 1 in the preterm infant. Surgery 2010; 148:404-10.

12. Chang DC, Salazar-Osuna JH, Choo SS et al. Benchmarking the quality of care of infants with low-risk gastroschisis using a novel risk stratification index. Surgery 2010; 147:766-71.

13. Anand KJ, Hopkins SE,Wright JA et al. Statisticalmodels to predict the need for postoperative intensive care and hospitalization in pediatric surgical patients. Intensive Care Med 2001; 27:873-83.
14. Weinberg $A C$, Huang $L$, Jiang $H$, et al. Perioperative risk factors for major complications in pediatric surgery: A study in surgical risk assessment for children. J Am Coll Surg 2011; 212:768-78.

15. Chow S, Choe R, Popovic M et al. A selected review of the mortality rates of neonatal intensive care units. Front public health 3:225.

16. Otake $\mathrm{K}$, Uchida $\mathrm{K}$, Kubo $\mathrm{M}$ et al. Clinical factors associated with in-hospital death in pedidiatric surgery patients admitted to the neonatal intensive care unit: A 15-year single tertiary center experience. J Pediatr Surg 2018; 53:499-502.

17. Hanif A, Hasina K, Hossain AZ et al. Neonatal Surgery: Demand and survival both are increasing: Eight years experience in Dhaka Medical College Hospital, Bangladesh. Journal of Pediatric Surgeons of Bangladesh 2010; 1(1):30-5.

18. Taguchi T. Current progress in neonatal surgery. Surgery Today 2008; 38:379- 89.

19. Lally KP, Lally PA, Van Meurs KP et al. Treatment evolution in high-risk congenital diaphragmatic hernia: Ten years' experience with diaphragmatic agenesis. Ann Surg 2006; 244:505-13.

20. Japanese $\mathrm{CDH}$ Study Group. Clinical guidelines for congenital diaphragmatic hernia of the newborn.https://www.mch.pref. osaka.jp/ hospital/department/shounigeka/cdh_guideline_02.pdf.

21. Ito $\mathrm{M}$, Japanese $\mathrm{CDH}$. Study group: Diagnosis, management and a national clinical guideline of congenital diaphragmatic hernia. J Jpn Soc Perin Neon Med 2016; 52:1-18.

22. Yamoto $M$, Nakazawa $Y$, Fukumoto $K$ et al. Risk factors and prevention for surgical intestinal disorders in extremely low birth weight infants. Pediatr Surg Int 2016; 32:887-93.

23. Eaton $\mathrm{S}$, Rees $\mathrm{CM}$, Hall $\mathrm{NJ}$. Current research in necrotizing enterocolitis. Early Hum Dev 2016; 97:33-9.

24. Frost BL, Modi BP, Jaksic T et al. New medical and surgical insights into neonatal necrotizing enterocolitis: A review. JAMA Pediatr 2016.

25. Morriss Jr FH, Saha S, Bell EF et al. Surgery and neurodevelopmental outcome of very low-birth-weight infants. JAMA Pediatr 2014; 168:746-54. 